\title{
A DIVISÃO NO ESPORTE DEVE SER SEPARADA POR SEXO OU GÊNERO
}

\section{LA DIVISIÓN EN EL DEPORTE DEBE SER SEPARADA POR SEXO O GÉNERO}

\section{THE SPORTS DIVISION MUST BE SEPARATED BY SEX OR GENDER}

Maria Eduarda Aguiar da Silva ${ }^{1}$

\begin{abstract}
Resumo
Artigo científico que tem objetivo analisar se a separação nos esportes deve ser por sexo biológico ou gênero, fruto de pesquisa iniciada em março de 2018 após a polêmica com a jogadora transexual de volei Tifanny Abreu. $\mathrm{O}$ trabalho enfoca a temática da divisão sexual nos esportes e se a separação deve ser por sexo biológico ou gênero auto identificado, enfrentando questões polêmicas que envolvem a idéia de vantagem ou desvantagem pretérita, ouvindo argumentos favoráveis e contrários a inclusão de atletas transexuais nos esportes.
\end{abstract}

Palavras chaves -Transexualidade. Separação sexual nos esportes. Sexo biológico. Gênero.

\begin{abstract}
Scientific article that aims to analyze whether the separation in sports should be by biological sex or gender, the result of research initiated in March 2018 after the controversy with the transsexual volleyball player Tyfanni Abreu. The work focuses on the issue of sexual division in sports and whether the separation should be by biological sex or self-identified gender, facing controversial issues involving the idea of past advantage or disadvantage, listening to arguments favorable and contrary to the inclusion of transsexual athletes in sports
\end{abstract}

Key words -Transsexuality. Sexual separation in sports. Biological sex. Genre.

\section{Resumen}

Artículo científico que tiene objetivo analizar si la separación en los deportes debe ser por sexo biológico o género, fruto de investigación iniciada en marzo de 2018 tras la polémica con la jugadora transexual de volei Tyfanni Abreu. El trabajo enfoca la temática de la división

Submetido em: 10/03/2019

Aceito em: 08/04/2019

Publicado em: 01/06/2019

${ }^{1}$ Advogada, graduada em Direito pela UNESA, Cursando pós de Genero e Direito na EMERJ. 
sexual en los deportes y si la separación debe ser por sexo biológico o género auto identificado, enfrentando cuestiones polémicas que involucran la idea de ventaja o desventaja pretérita, oyendo argumentos favorables y contrarios a la inclusión de atletas transexuales en los deportes

Palabras claves -Transexualidad. Separación sexual en los deportes. Sexo biológico. Género.

\section{INTRODUÇÃO}

A população de mulheres transexuais e travestis historicamente luta por direitos básicos de cidadania, tal como direito ao nome, direito ao respeito de sua identidade e inclusão dentro da sociedade.

No ano de 2018, a partir de 21 de Janeiro de 2018, tomou conta dos noticiários o caso da atleta de vôlei, Tifanny, acerca da sua aceitação como jogadora na categoria feminina pelo Comitê Olimpíco Internacional - COI. ${ }^{2}$

A polêmica se originou a partir da alegação, de algumas jogadoras, de que uma mulher transexual ou mulher transgênero teria uma força fisica maior que jogadoras que fossem mulheres cisgeneras.

Isso se deve principalmente pelo desempenho espetacular que a alteta tem tido, no ano de 2018, em cinco jogos foram 115 pontos, média de 23 por partida e um desempenho superior ao da oposta Tandara, do Osasco e da seleção brasileira, maior pontuadora da competição com média de 20 pontos.

Segundo o Comitê Olímpico Internacional, não é necessário fazer a cirurgia de redesignação sexual (CRS) para disputar competições femininas. Basta ter um nível de testosterona abaixo de 10 nanomols por litro de sangue.

O presente trabalho visa, então, analisar as questões juridicas e de gênero envolvendo o caso sendo necessário adentrar sobre as controvérsias ligadas a biologia.

O primeiro capitulo visa entender e analisar como a heteronormatividade e a marginalização dos corpos trans (travestis e mulheres transexuais) contribuem para o processo

${ }^{2}$ Reportagem, Caso Tiffany: Sheilla vê vantagem física e se diz contra; opinião gera polêmica, <http://esporte;ig;com;br/maisesportes/volei/2018-01-21/caso-tiffany-sheilla.html>, acessado em 26 de fevereiro de 2019. 
de desumanização e violência em que é vítima a população de mulheres transexuais e travestis.

O segundo capitulo analisa como os especialistas tem tratado a matéria trazendo argumentos contrários e favoráveis a permanência de atletas transexuais nos esportes.

Por fim, o terceiro capitulo visa analisar a inclusão de atletas transexuais no esporte de acordo com os estudos de gênero e legislação vigente.

A pesquisa será desenvolvida pelo método dedutivo, uma vez que a pesquisadora pretende eleger um conjunto de proposições, as quais acredita serem viáveis e adequadas para analisar o objeto da pesquisa, com o fito de comprová-las argumentativamente.

Para tanto, a abordagem do objeto desta pesquisa jurídica será necessariamente qualitativa, porquanto a pesquisadora pretende se valer da bibliografia pertinente à temática em foco - analisada e fichada na fase exploratória da pesquisa (revistas, artigos correlatos, legislação e doutrina) - para sustentar a sua tese.

\section{A heteronormatividade e a marginalização dos corpos trans (travestis e mulheres transexuais). Como esse processo contribui para o processo de desumanização e violência.}

De acordo com Vagner Matias do Prado e Alessandra Lo Gullo A Nogueira (2018) o conceito de heteronormatividade, cunhado por Michael Warner (1993) é compreendido como um padrão de sexualidade que regula o modo como as sociedades ocidentais estão organizadas, trata-se de determinar dentro da sociedade quais são as identidades e a sexualidades socialmente aceitas ${ }^{3}$.

Nesse aspecto, a heteronormatividade visa controlar corpos e sexualidades. De acordo com o sistema normativo vigente há duas formas de ver a anatomia sexual humana: homem ou mulher a partir de sua genitália e com relação a sexualidade só se admite a orientação heterossexual, ignorando-se os diversos recortes de gênero e sexualidade existentes, tais como homem trans, mulher transexual, travesti, pessoa não binária, homossexual, lesbica, bissexual dentre outras formas de sexualidade e gênero.

\footnotetext{
${ }^{3}$ Michael Warner, Fear of a Queer Planet, 1993. Crítico literário americano, teórico social, e Seymou H Knox, professor de Literatura Inglesa e Estudos Americanos da Universidade de Yale. ele também escreve para Artforum, The Nation, The Advocate e The Vilage Voice.
} 
Conforme ressalta Guaciara Louro $(1999)^{4}$, há uma lógica na representação hegemônica do gênero e da sexualidade que definiria uma coerência "natural" e "inerente" entre sexo-gênero-sexualidade, isto é, cada sexo só poderia interessar-se pelo sexo oposto (sexualidade heterossexual) e este interesse seria ratificado pela possibilidade procriativa.

Essa linha de pensamento vem de uma lógica biologizante que entende que "homem nasce homem" e "mulher nasce mulher", a partir de suas genitálias, negando direito a identidade a quem transgride as normas vigentes de gênero - travestis, mulheres transexuais e homens trans.

A influência da heteronormatividade sobre os corpos trans promove um verdadeiro processo de desumanização, entendendo desumanização como vulnerabilização induzida e produção de abjeções. Os reflexos desse processo de marginalização é a transfobia e falta de acesso aos espaços de educação, trabalho, e família constituindo a vida de pessoas transexuais em uma vida sub-humana, em indivíduos sem acesso aos direitos básicos de cidadania e vivência em sociedade.

Em relação as violências vivenciadas por mulheres transexuais e travestis estão o cerceamento do direito a vida, a cidadania, sem falar da violência simbólica, esta entendida quando os lugares se tornam não lugares, como exemplo prático podemos citar a expulsão do seio familiar e da escola.

A violência praticada contra travestis e mulheres transexuais é acentuada devido a invisibilidade dentro da sociedade, principalmente para questões de violência física e assassinatos, como exemplo podemos citar a performance da travesti Viviane Beleboni na 19a Parada LGBT de São Paulo de 2015, cuja performance era sua imagem crucificada em um dos trios (Vagner Matias do Prado e Alessandra Lo Gullo A Nogueira, 2018).

Segundo Buthler ${ }^{5}$ (2015, p 17):

\begin{abstract}
“os esquemas normativos são interrompidos um pelo outro, emergem e desaparecem dependendo de operações mais amplas de poder, e com muita frequência se deparam com versões espectrais daquilo que alegam conhecer. Assim, há sujeitos que não são exatamente reconhecíveis como sujeitos e há vidas que dificilmente ou nunca são reconhecidas como vidas".
\end{abstract}

\footnotetext{
${ }^{4}$ Guaciara Lopes Louro. Doutora em Educação e Professora titular aposentada do Programa de Pós Graduação da Universidade Federal do Rio Grande do Sul.

${ }^{5}$ Judith Butler, filósofa pós-estruturalista estadunidense, umas das principais teóricas da questão contemporânea do feminismo, teoria queer e ética. Ela é professora do departamento de retórica e literatura comparada da Universidade da Califórnia em Berkeley.
} 
Dessa forma, a reação negativa que a performance de Viviane Beleboni ${ }^{6}$ foi encarada pela sociedade revela quais vidas são reconhecidas como importantes e quais vidas não importam.

Caso similar aconteceu com a atriz Renata Carvalho ${ }^{7}$, ao interpretar a peça " $\mathrm{O}$ Evangelho de Jesus segundo Rainha do Céu", onde Jesus Cristo é uma travesti, é uma nítida provocação ao conservadorismo religioso.

A peça em questão recebeu duras criticas, por partes de certos grupos religiosos, de estar profanando a religião cristã, uma vez que, no imaginário de alguns coletivos de pessoas ser comparado a uma travesti é ofensa grave. Vale dizer, inclusive, que a atriz recebeu diversas ameaças, processos judiciais que tentaram censurar a peça, o que demonstra o ódio e o desprezo que alguns setores da sociedade sentem por travestis e mulheres transexuais.

Indubitavelmente o Brasil é o país que mais mata travestis e transexuais ao atingir a marca de 179 mortes em 2017 (ANTRA - Associação Nacional de Travestis e Transexuais).

Em relação a exclusão escolar cabe algumas considerações. Ao serem expulsas de casa, as mulheres transexuais não conseguem se manter dentro da estrutura formal de ensino. Passam a não mais se enxergar como cidadãs e tem suas possibilidades de qualificação ou realização profissional comprometidas.

Como segunda instituição de acesso social, e a primeira fora do seio familiar. A escola concentra o maior expectro daquilo que as pessoas aprendem em suas famílias. Os valores, a religiosidade, a intolerância ao diferente e consequentemente como reagir a isso são ensinados aos seus membros para que não se aproximem ou se misturem a quem está errado e merece ser isolado, se possível, excluído do convívio.

Pesquisas demonstram que $1 / 4$ estudantes NÃO gostariam de ter um colega de classe Transexual. A mesma rejeição explícita, apareceu inclusive entre professores, ainda que em menor grau. (UNESCO, 2004).

O Brasil concentra cerca de $82 \%$ de exclusão escolar das pessoas Trans (ANTRA/Afroreggae); $59 \%$ das pessoas trans não possui o ensino fundamental; $68 \%$ não possui o ensino médio; e apenas $0,02 \%$ estão no ensino Superior.

\footnotetext{
${ }^{6}$ Viviane Beleboni, Transexual ficou conhecida mundialmente após aparecer "cricificada" durante a parada LGBT de São Paulo no ano de 2015.

${ }^{7}$ Renata Carvalho, atriz transexual, protagonista da peça " O Evangelho Segundo Jesus, Rainha do Céu". Peça que retrata o calcário de um Jesus Cristo cujo crime-mor foi ter nascido transexual.
} 
Um dos fatores que contribuem para que a escola seja um não lugar para pessoas Transexuais é a proibição da discussão de gênero nas escolas, nos programas municipais e estaduais de educação orquestrado por grupos ultraconservadores tem mantido a proibição, que vem sendo derrubada nos tribunais de justiça do Estado, tendo o próprio Ministro Luis Roberto Barroso se manifestando pela inconstitucionalidade da proibição na ADPF 465.

"A Constituição estabelece expressamente como diretrizes para a organização da educação a promoção do pleno desenvolvimento da pessoa, do desenvolvimento humanístico do país, do pluralismo de ideias, bem como da liberdade de ensinar e de aprender.

Quanto maior é o contato do aluno com visões de mundo diferentes, mais amplo tende a ser o universo de ideias a partir do qual pode desenvolver uma visão crítica, e mais confortável tende a ser o trânsito em ambientes diferentes dos seus", observou, ao considerar presente a plausibilidade da inconstitucionalidade formal e material do dispositivo questionado "

Outro ponto importante a ser ressaltado, é que em que pese a resolução 12 do Conselho Nacional de Combate a Discriminação e a Resolução 01/2018 do MEC garantirem o uso do nome social e de banheiro conforme o gênero nas escolas públicas e privadas ainda se encontra resistência no cumprimento desse direito, que acaba tendo que ser dirimido no poder judiciário.

Essa triste realidade provoca a não capacitação para entrada no mercado formal de trabalho e aliada ao preconceito se torna uma barreira quase intransponível, como resultado não vemos pessoas trans nas diversas atividades laborais cotidianas.

Por isso a lógica social heteronormativa é de tentar excluir travestis e mulheres transexuais de todos os espaços, criando sempre uma barreira quase que intransponível para que essas mulheres possam ser reconhecidas como pertencentes do gênero feminino e principalmente como pessoas que fazem parte do estado brasileiro, com direito a cidadania plena e não ser tratada como pária da sociedade.

Dessa forma, se mostra extremamente relevante refletir se a separação nos esportes deve ser por sexo biológico ou gênero e como os processos de exclusão social transformam lugares em não lugares - família, escola e trabalho - para pessoas transexuais. 


\section{Separação sexual nos esportes: o que dizem os especialistas}

O fisiologista Turíbio Barros ${ }^{8}$ entende que apesar dos níveis de testosterona de uma atleta transexual ser identico ao de uma mulher cisgenera, haveria uma vantagem pretérita devido aos anos de crescimento com uso de testosterona.

Já Cyd Zeigler", autor do estudo "Fair Play: How LGBT Athletes are Claiming Their Rightful Place in Sport”, entende que essa "vantagem" não garante maior capacidade física do que uma atleta que não teve essa influência de hormonio no seu crescimento.

Segundo estudo chamado "Race Times for Trangender Athletes", do Providence Protland Medical Center, de Joanna Harper ${ }^{10}$, o tratamento hormonal de mulheres transexuais produz um decréscimo significativo de massa corporal e densidade óssea.

A Federação Internacional de Vôlei reafirma a regra atual do Comitê Olímpico Internacional definindo que de acordo com as regras do COI, homens trans podem participar de competições masculinas sem restrições. Já mulheres transexuais e travestis precisam preencher quatro condições para disputar competições na categoria feminina: 1) declarar ser do gênero feminino (reconhecimento civil que deverá por no mínimo 4 anos para efeitos esportivos), 2) ter nível de testosterona inferior a 10 nanomols nos 12 meses anteriores ao primeiro jogo, manter o nível de testosterona inferior a 10 namomols durante o período elegível para competir e 3) ser submetida a testes frequentes para monitorar a testosterona. Não é mais necessário ter passado por cirurgia de resignação sexual.

Importante ressaltar que para atingir o nível exigido a mulher transexual passa por um rigoroso acompanhamento e regular terapia hormonal que possibilita o equilíbrio hormonal no mesmo patamar de mulheres ditas cigêneras, as que biologicamente nasceram no sexo feminino e assim se reconhecem.

$\mathrm{O}$ assunto é polêmico e divide especialistas Dra Karen ${ }^{11}$, médica endocrinologista do IEDE - Instituto de Endocrinologia e Diabetes do Estado do Rio de Janeiro - faz uma análise técnica atleta tem privilégios perante as outras jogadoras do time feminino.

\footnotetext{
${ }^{8}$ Dr turibio Barros, Mestre e doutor em fisiologia do Exercício. Professor Adjunto da UNIFESP Membro do Conselho Regional de Biomedicina, Consultor em Fisiologia do Exercício. Autor de livros sovre ciências do esporte, fisiologia do exercício, saúde e qualidade de vida.

${ }^{9}$ Cyd Zeigler, é comentarista e autor no campo da sexualidade e esportes. Zeigler foi co-fundados da Outsports e da National Gay Flag Football League.

${ }^{10}$ Joanna Harper, assessora do COI em assuntos de gênero e esporte, fisico médico de profissão, corredor ávido por escolha e a unica pessoaa publicar um artigo revisado por pares sobre o desempenho de atletlas transgenero.

${ }^{11}$ Karen Seidel, endocrinologista do Instituto de Endocrinologia e Diabetes do Estado do Rio de Janeiro e coordenadora do ambulatório trans, referenciado para atendimento ambulatorial no processo transexualizador.
} 


\begin{abstract}
"Por mais que os níveis de testosterona estejam bastante reduzidos, ainda mantém sua estrutura óssea muscular e visceral de um indivíduo masculino, podendo ter uma performance superior de suas colegas"
\end{abstract}

De acordo com a pesquisadora Joanna Harper, do Providence Portland Medical Center, nos Estados Unidos, a diminuição da testosterona é suficiente para igualar as competidoras

transexuais às mulheres biológicas, chamadas de cis. Esse teste seria satisfatório para provar que as atletas podem competir juntas.

\footnotetext{
"Terapia hormonal para mulheres trans normalmente envolve um bloqueador de testosterona e um suplemento de estrógeno. Quando os níveis do 'hormônio masculino' se aproximam do esperado para a transição, a paciente percebe uma diminuição na massa muscular, densidade óssea e na proporção de células vermelhas que carregam o oxigênio no corpo", diz Joanna.
}

Ainda conforme pontuou a especialista, enquanto isso, o estrógeno aumenta as reservas de gordura, principalmente nos quadris. Juntas, essas mudanças levam a uma perda de velocidade, força e resistência — todos componentes importantes de um atleta.

Durante a terapia hormonal, Tifanny perdeu toda a potência e explosão. Se saltava $3,50 \mathrm{~m}$ quando "homem", agora pula, no máximo, 3,25m. O número ainda é alto se comparado a outras jogadoras de altura parecida, informou a profissional.

Tifanny tem 1,94m, a central Thaísa, de 1,96m, salta 3,16m, o mais alto do país. Mas, fora daqui a italiana Paola Egonu alcança os 3,36m, e a chinesa Ting Zhu, 3,27m. Wallace, oposto da seleção masculina, mesma posição de Tifanny, chega aos 3,44m.

Regis Rezende, (Professor de Educação Física e Fisiologista formado pela PUC-GO, Pós-Graduado e Especialista em Voleibol pela Universidade Gama Filho-RJ, CREF: 004202G/GO, com as revisões de Adriano Passos Doutorando em Sociologia - PPGS/UFG; Mestre em Sociologia - PPGS/UFG; Graduado em Educação Física; Especialista em Fisiologia do Exercício, Avaliação Morfofuncional, Atividade Física Adaptada e Saúde) publicou na revista melhor do vôlei estudos mostram que em alguns esportes a performance de atletas submetidas à terapia hormonal é inclusive abaixo de mulheres cisgênero.

Para Rezende a biologia não deve ser neutra nem axiológica tampouco metodologicamente citando Pierre Bordieu, fazendo uma critica ao que considera "achismos" sobre o tema em relação a critica sobre a presença de grupos estigmatizados e invizibilizados nos esportes. 
Ainda se baseando no estudo de Joanna Harper ele cita que uma pesquisa com atletas corredores de provas de rua e concluiu que as atletas transexuais que foram submetidas a terapia de reestabelecimento hormonal passaram a alcançar tempos até $12 \%$ inferiores aos alcançados um ano antes da terapia.

Apresenta ainda algumas peculiaridades em relação ao voley masculino e feminino destacando que: 1) o sistema defensivo não é igual; 2) que os saques dos jogos femininos são mais flutuantes que o masculino e 3 ) as posições de defesa são diferentes, tendem a ser mais baixas para mulheres.

Ao abordar o caso específico da atleta Tifanny ele desta que ela sacou na Superliga 27 vezes nos 3 jogos e fez 3 pontos de saque, media de um (1) ponto de saque por jogo. A atleta jogou 13 sets o que faz sua média de saque de diminuir para 0,23 pontos por set.

\begin{tabular}{|c|c|c|c|c|}
\hline J ogo & $\begin{array}{l}\text { Ptos de } \\
\text { Ataque }\end{array}$ & $\begin{array}{c}\text { Número de Bolas } \\
\text { Atacadas }\end{array}$ & Sets Jogados & $\begin{array}{c}\text { Efíciência } \\
(\%)\end{array}$ \\
\hline São Caetano & 14 & 35 & 4 & $40 \%$ \\
\hline Pinheiros E.C & 24 & 44 & 4 & $54 \%$ \\
\hline $\begin{array}{l}\text { Fluminense } \\
\text { F.C }\end{array}$ & 26 & 63 & 5 & $41 \%$ \\
\hline TOTAL & 64 & 142 & 13 & $45 \%$ \\
\hline
\end{tabular}

(Gráfico retirado de http://www.melhordovolei.com.br/a-multilateralidade-da-biologia/)

Em análise aos números Regis Rezende destaca que:

"Em eficiência ela tem a maior média de pontos por SET (também não a faz maior pontuadora da competição como as notícias tendem a dizer) e essa afirmação não a coloca como a melhor jogadora do torneio, aliás $45 \%$ de aproveitamento no ataque não a coloca entre as 5 melhores atacantes da competição (a jogadora líder nas estatísticas de ataque de acordo com os dados da CBV é Walewska Oliveira com 60\% de aproveitamento no ataque), ou seja, a atleta não é um "ponto fora da curva", quando se percebe os números de ações de suas companheiras de equipe. Ela foi bloqueada, foi defendida e errou ataques na mesma proporção de qualquer outra jogadora que disputa o torneio"

Percebe-se que pelos estudos apresentados que o nível hormonal e de massa muscular de mulheres transexuais se equivalem a de mulheres cisgeneras, não havendo segundo os estudos pesquisados vantagem quando preenchido os requisitos e exigências estabelecidas pelo Comitê Olímpico Internacional. 
Inclusão de atletas trans no esporte de acordo com os estudos de gênero e legislação vigente

As discussões sobre inclusão de pessoas transexuais nos esportes ainda são muito polêmicas, devido, ainda pouca literatura e pesquisas sobre essa questão. A inclusão de atletas trans nos esportes, sem precisar de autorização prévia dos comitês tem como marco o " $V$ Gay Games de Nova York" em 1994, evento cultura e esportivo organizado para comunidade LGBT+

Em relação aos Jogos Olímpicos, o Comitê Olímpico Internacional em 2015 editou diretrizes para inclusão de transexuais nos esportes.

Renee Richards foi uma das primeiras representantes transexuais, na modalidade competitiva na disputa de jogos de tenis de campo individual, década de 1970.

"Renée Richards se tornou, oficialmente, "a primeira transexual da história da modalidade". Ou assim foi registrado pela historia oficial do esporte! Em que pese essa classificação ser importante para identificar para alteridade e outras identidades sexuais e de gênero no campo esportivo, Richards preferia que ela fosse considerada como outra mulher qualquer (Camargo, 2018, p.1)"

No ano de 2016, na Itália, o cenário do volei teve modificações com a contratação da libero Alessia Ameri, de 30 anos. A primeira "trans" a jogar em uma partida oficial de vôlei do campeonato italiano, atleta da equipe Hermae Entu da série A2.

\section{Os Estudos de gênero e o que diz a legislação vigente}

Os estudos de gênero, em regra, favorecem rejeição pelo determinismo biológico, entendendo que existem fatores relacionais e culturais de construção social do feminino e do masculino.

Trago a reflexão, os estudos intitulados Gay and Lesbian Studies e a Queer Theory, que faz um contraponto entre corpo e identidade de gênero. Os movimentos sociais de afirmação identitária, movimento de travestis e transexuais, por ex, vem por anos reinvidicando espaço questionando a construção cultural da sociedade vigente, fazendo um antagonismo entre construção cultural e diferença anatômica. 
Segundo Thomas Laqueur a diferença entre os sexos é uma invenção para promover desigualdades, não que as diferenças corporais não fossem percebidas, mas até o final do século XVIII os sexos não eram entendidos como opostos e incomensuráveis, surgindo a partir de então a segregação de gênero, que vigora até hoje, promovendo uma serie de discussões, em especial, quando envolve outras identidades sexuais, não contempladas pela cis heteronormatividade.

Assim, os estudos de gênero questionam a imutabilidade do sexo, entendimento defendido por Laqueur, Judith Butler e Strathem.

Entretanto a pergunta fica: a divisão de categorias esportivas deve ser separada por sexo ou gênero.

Se faz necessário conceituar sexo e gênero, onde sexo nos remete às diferenças biológicas naturais do corpo: cromossomos, perfil hormonal, órgãos sexuais internos e externos e gênero se refere a construção social e cultural das diferenças sexuais, aquilo que se considera como característica masculina e feminina.

A discussão gira em torno de duas visões antagônicas: a visão essencialista e a construtivista, na visão essencialista, os defensores(as) da tese que a jogadora Tifanny teria vantagem física se baseiam numa lógica biológica.

Dentre as pesquisadas, a teoria construtivista figura-se a mais inclusiva, entendendo que gênero é construção social e que os estudos apontam que uma mulher transexual em TSH ( Terapia Sexual Hormonal) costuma correr 12\% mais devagar do que antes, ou seja, comprovadamente ocorre perda de força, massa muscular e densidade óssea (Harper). Imagine uma pessoa com corpo fisico maior mas com força fisica menor, nesse contexto a pessoa teria que fazer muito mais força para manter o mesmo nivel que uma pessoa menor com a mesma força fisica.

“(...) a mulher transexual é uma mulher que, no processo de resignificação, ingere bloqueio de hormônios (testosterona), ou seja, ela tem menos testosterona no organismo do que as suas concorrentes, demandando maior treinamento para manter massa muscular e a força do que uma atleta mulher nascida fêmea. (...) (GRESPAN; GOELLNER, 2014, P. 1268)"

Dessa forma, os discursos contrários a inclusão das mulheres transexuais no esporte demonstram uma clara transfobia dentro do cenário esportivo, De Jesus (2014) afirma que:

"No que se refere ao seu cotidiano, as pessoas transgênero são alvo de preconceito, desatendimento de direitos fundamentais ( diferentes organizações não lhe permitem utilizar seus nomes sociais e elas não conseguem adequar 
seus registros civis na justiça), exclusão estrutural (acesso dificultado ou impedido à educação, ao mercado de trabalho e até mesmo ao uso de banheiros) e de violências variadas, de ameaça a agressões e homicídios, o que configura a extensa série de percepções estereotipadas negativas e de atos discriminatórios contra homens e mulheres transexuais e travestis denominada "transfobia" ( De Jesus, 2014, p.105-106)

Portanto, eu entendo que obedecendo os critérios estabelecidos pelo COI não existe vantagem atual ou pregressa de atletas transgêneros nos esportes.

E mais, a Constituição da República federativa do Brasil de 1988, garante no art.1, III o princípio da dignidade da pessoa humana e no seu art. $3^{\circ}$, IV a proibição de quaisquer formas de discriminação.

Entendendo a atuação das atletas como trabalho, destaco o seguinte trecho do livro Gênero e Desigualdades de Flavia Biroli:

"Permanece, portanto, a necessidade enfrentar os padrões de gênero nessas hierarquias, considerando a produção de gênero nas relações de trabalho levando em conta a interseção de gênero, classe e raça".

Portanto, se basear única e exclusivamente nos aspectos biológicos irá gerar uma desigualdade e discriminação muito grande há um número considerável de mulheres transexuais conhecido como transfobia social ou estrutural, fato, que já ocorre em diversas áreas do mercado de trabalho, lembrando que $90 \%$ da população de mulheres transexuais e travestis estão na prostituição e 179 mulheres transexuais e travestis foram assassinadas por crime de ódio só em 2017 ( ANTRA, 2018).

\section{CONCLUSÃO}

A divisão no esporte, portanto, a meu sentir se for feita com base no sexo biológico, irá inviabilizar que uma mulher transexual consiga reconhecimento de sua identidade de gênero dentro da categoria feminina, já a divisão por gênero constitui o reconhecimento das múltiplas identidades que fazem parte do sexo feminino, incluindo-se nesse contexto as mulheres transexuais, motivo pelo qual entendo que a divisão da categoria no esporte deve ser feita por gênero, levando-se em conta o percentual de testosterona e que o processo de hormonização de 2 anos ou mais provoca perda de massa muscular e densidade óssea. 
Há de ser considerado também que a constituição federal veda qualquer forma de discriminação e tem como principio fundamental a dignidade da pessoa humana. ( art. $1^{\circ}$, III e art. 3, IV, ambos da CF/88).

Estando a atleta dentro das regras estabelecidas para qualquer mulher e sendo conclusivos os estudos pela não prevalencia de vantagem pretérida associada ao gênero não cabe qualquer segregação ou discriminação, sob pena de estar-se cometendo grave atentado aos direitos humanos das mulheres transexuais.

Por esse motivo que entendo pela inclusão das mulheres transexuais nas categorias femininas de esporte, desde que cumpridos os requisitos exigidos pelo Comitê Olimpico Internacional.

\section{REFERÊNCIAS BIBLIOGRÁFICAS}

GOMES, Carla e SORJ, Bila. Corpo, Geração e Identidade. Soc. Estado vol.29 n². Brasília, 2014.

BIROLI, Flavia. Gênero e Desigualdades. Editora Boi tempo, 2018

ESPORTE, Globo. Reportagem sobre polêmica envolvendo a jogadora Tyffani Abreu. Esporte espetacular.<https://globoesporte.globo.com/programas/esporte-espetacular/noticia/envolvidaem-polemica-tiffany-desabafa-forca-de-uma-mulher.ghtml. , acesso em 18.03.2018 >

ESPORTE, Globo. Fisiologista ve beneficios pregesso para atletas transgêneros mas Comite Olimpico Internacional abre espaço". <https://globoesporte.globo.com/olimpiadas/noticia/fisiologista-ve-beneficio-pregresso-mascoi-abre-espaco-para-transgeneros.ghtml>, acesso em 18.03.2018

NLUCON. Inclusão de atletlas trans nos esportes e polêmica do caso Tyfanni Abreu. Inclusão de Altetas Trans nos Esportes <http://www.nlucon.com/2017/03/atletas-trans-levamvantagens-em.html>, acesso em 18.03.2018

ENDOCRINOLOGIA, Sociedade Brasileira. Analise da Sra Karen Seidel. Transexualidade no Esporte. <https://www.endocrino.org.br/transsexualidade-no-esporte>, acesso em 27.01.2019

HUFFPOSTBRASIL. Transgêneros tem que ser incluídos nos esporte diz federação. Atletas Transgêneros tem que ser incluídas nos esportes. 
<https://www.huffpostbrasil.com/2018/01/24/transgeneros-tem-de-ser-incluidos-no-esportediz-federacao-internacional-de-volei_a_23342720/, acesso em 27.01.2019>

PRADO, Vagner Matias e NOGUEIRA, Alessandra Lo Gullo A. Transexualidade e esporte: o caso Tyfane Abreu em jogo. Revista Eletrônica de Interações Sociais, 2018

REZENZE, Regis. Melhor do vôlei. A multilateralidade da biologia. <http://www.melhordovolei.com.br/a-multilateralidade-da-biologia/>, acesso em 14.04.2019

ANTRA. Relatório de assassinatos. Mapa dos Assassinatos de Travestis e Transexuais no Brasil. https://antrabrasil.files.wordpress.com/2018/02/relatc3b3rio-mapa-dos-assassinatos2017-antra.pdf , acesso em 28/04/2018 